\title{
Narrativas: um olhar sobre o exercício historiográfico na Educação Matemática
}

\section{Narratives: a look at the historiographical exercise in Mathematics}

\author{
Education
}

\author{
Fernando Guedes Cury* \\ Luzia Aparecida de Souza** \\ Heloisa da Silva ${ }^{* * *}$
}

\begin{abstract}
Resumo
Este artigo apresenta algumas das discussões que tem marcado a prática investigativa do grupo "História Oral e Educação Matemática" (GHOEM). A História Oral se apresenta como uma metodologia de pesquisa qualitativa cujo foco principal é a construção de narrativas a partir de situações de entrevista. Este texto discute algumas perspectivas vinculadas ao uso de análise (narrativa) de narrativas na/para a História da Educação Matemática.
\end{abstract}

Palavras-chave: Educação Matemática. História Oral. Narrativas.

\begin{abstract}
This paper presents some of the discussions that has marked the investigative practice of the Group "Oral History and Mathematics Education" (GHOEM). For these researchers the oral history is faced like a qualitative research methodology, whose main focus is the construction of narratives from interview situations. This paper discusses some perspectives related to the use of (narrative) analysis of narratives in/for the History of Mathematics Education.

\footnotetext{
* Doutor em Educação Matemática pela Universidade Estadual Paulista/UNESP, campus de Rio Claro (SP). Professor do Departamento de Matemática da Universidade Federal do Rio Grande do Norte/UFRN. Endereço para correspondência: Av. Sem. Salgado Filho, 3000, Bairro Lagoa Nova, CEP: 59078-970, Natal, RN, Brasil. E-mail: matfernando@yahoo.com.br.

${ }^{* *}$ Doutora em Educação Matemática pela Universidade Estadual Paulista/UNESP, campus de Rio Claro (SP). Professora do INMA - Instituto de Matemática da Universidade Federal de Mato Grosso do Sul (UFMS). Endereço para correspondência: Av. Costa e Silva, s/n, Bairro Cidade Universitária. CEP: 79070-900, Campo Grande, MS, Brasil. E-mail: luzia.souza@ufms.br.

**** Doutora em Educação Matemática pela Universidade Estadual Paulista/UNESP, campus de Rio Claro (SP). Professora do Departamento de Matemática da Universidade Estadual Paulista/UNESP, campus de Rio Claro. Endereço para correspondência: Av. 24-A, nº. 1515, Bairro Bela Vista, inserir o CEP: 13506-900, Rio Claro, SP, Brasil.E-mail: heloisas@ rc.unesp.br.
} 
Keywords: Mathematics Education. Oral History. Narratives.

\section{Introdução}

O uso de narrativas em abordagens que consideram aspectos sociológicos e culturais nos estudos em Educação Matemática foi sempre comum, mas pode-se dizer que ele tem sido intensificado nos trabalhos de pesquisa desse campo. Nas pesquisas preocupadas com o ensino e a aprendizagem de Matemática, a narrativa tem funcionado como método de exploração dos modos de produção de significados para objetos matemáticos pelos alunos. A Etnomatemática que sempre utilizou estratégias da antropologia nos registros de caracterização das diferentes etnias, vale-se das narrativas, sobretudo através dos diários de campo e entrevistas. A Filosofia da Educação Matemática, continuamente preocupada em discutir a pertinência, a legitimidade e necessidade de se abordar o conhecimento matemático, bem como sua produção, apropriação, ensino e aprendizagem, utiliza nomeadamente entrevistas e experimentos de ensino, em que se destacam as fontes narrativas, analisando-os sob os mais diversos vieses teóricos.

Por também considerar os aspectos sociológicos e culturais em suas pesquisas ao longo da última década, a linha de pesquisa da História da Educação Matemática, através da História Oral, vem priorizando a fonte narrativa em trabalhos cujo tema evidente tem sido o da duração, na busca por compreender as alterações e permanências no quadro temporal e espacial no qual se movem sujeitos e grupos.

Tal priorização vê nas narrativas orais a possibilidade de explorar diversos olhares sobre situações históricas e ampliar os significados sobre elas de modo que se possam compreender aspectos que de outro modo talvez nem fossem abarcados. Com isso, o estudo aprofundado das narrativas e sua teorização por pesquisas na linha da História da Educação Matemática através da História Oral se tornaram indispensáveis.

\section{Os usos da narrativa: mito, história, ficção}

O que se observa nos contos tradicionais em relação à repetição de estruturas, de enredos, de expressões, é parte da construção de uma narrativa que, inicialmente, além da voz, 
valia-se do gesto, da dança, da música, da batida do tambor para encantar o ouvinte. Nessas cerimônias,

a palavra não tem valor ou peso por si mesma, ela tem valor enquanto ritmo, enquanto marcação, enquanto cadência. Ela não se manifesta enquanto sabedoria, mas enquanto música, enquanto melodia. E é por isso que é capaz de convencer. Por isso ela tem a força de repor nos homens a energia que se vinha abatendo. (SEVCENKO, 1988, p. 127).

A narrativa do mito era, portanto, uma performance comunitária já que dela derivam a música e a coreografia. As narrativas eram metrificadas, cantadas, dançadas. Mas estas experiências xamânticas ${ }^{1}$ foram por muito tempo classificadas como formas de loucura provisória. Segundo Sevcenko (1988), Sócrates define de forma clara este preconceito ao atribuir aos poetas uma inspiração instintiva como a dos videntes ou profetas, ao invés de uma sabedoria consciente, e aos filósofos a capacidade de analisar pela razão a existência da verdade e da justiça.

Tendo como referencial o movimento historiográfico, consideramos relevante citar uma partição da História, ocorrida no século XIX, quando ficaram delineadas a História-arte e a História-ciência, no momento em que veio à cena o historiador profissional (ou o profissional chamado historiador). A História-arte pode ser definida como uma narrativa que recria acontecimentos como se fossem presentes e, a partir da qual, o historiador nos fornece imagens do passado, sendo necessário contar com uma imaginação projetiva, o que tornaria explícitas sua vivência e experiência como narrador, aproximando-o, portanto, de um artista. Por outro lado, para a História-ciência, a narrativa como relação dos acontecimentos encadeados seria uma etapa preparatória de uma generalização indutiva, caminho para um verdadeiro conhecimento histórico. Para os adeptos desta última linha, como aponta Pomian (apud NUNES, 1988), aquela imaginação projetiva, ligada à vivência do historiador, seria deixada de lado, dando espaço para a razão como garantia de uma objetividade. Entretanto, esta busca pela objetividade, no fim das contas, resultou em simples narrativas com o encadeamento dos acontecimentos que pretendiam contar, ou em edições críticas de fontes já conhecidas (ibidem).

\footnotetext{
${ }^{1}$ Em face de uma sociedade em formação, unida pela necessidade da sobrevivência e "iniciada" nas artes, surge um tipo que, sob diferentes roupagens, com outros nomes, permanece até hoje. Os xamãs eram, entre outras coisas, os pintores das cavernas ou produtores de alguma forma de arte visual. Nas rodas em torno do fogo, no interior das cavernas, o xamã usava de suas responsabilidades para narrar histórias que serviam para as mais diversas atribuições: desde um ritual para decisões importantes até a libertação das tarefas do cotidiano.
} 
Essas duas formas de se encarar a História, a da narrativa e a da pesquisa, a do historiador-escritor e a do historiador-pesquisador, teriam favorecido sua passagem para o campo das Ciências Sociais, o que acabou acarretando o abandono da narrativa dos melhores mestres, mais próxima do labor artístico, posto que a modernidade buscou a institucionalização do conhecimento histórico.

Mas se admitimos uma vinculação entre Ficção, Ciência e Historiografia, pensando esta última, de maneira simples, como a investigação, uma prática voltada ao registro de fatos sociais das civilizações recorrendo, segundo Nunes, às leis gerais das ciências, inclusive fazendo uso da Ficção - que por intermédio do romance ou do drama pode alcançar um nível de generalidade semelhante ao do pensamento científico -, então o caráter de Ciência conquistado pelo conhecimento histórico não deveria suprimir a base narrativa que mantém sua ligação com o ficcional.

Com relação à entrada da narrativa na teoria da história, o autor considera que se dá através da inteligibilidade da história (story) e seu prosseguimento também remonta à précompreensão da ação. Assim, segundo o autor, "estamos sempre dentro do mesmo círculo hermenêutico que circunscreve a temporalidade da História e da Ficção" (ibid.), já que se o tempo de ambas é narrado e configurado, tal articulação da experiência temporal encontra-se antes esboçada no mundo-da-vida, onde duas espécies narrativas se arraigam.

A leitura de uma obra historiográfica refigura, por sua vez, o tempo. "A imaginação se faz visionária: 'o passado é o que eu teria visto, aquilo de que eu teria sido testemunha ocular, se estivesse estado lá, como o outro lado das coisas é aquele que eu veria se as percebesse de onde você as considera'"(ibid.). Assim, o autor conclui que a leitura ficcionaliza a História e, em compensação, historiciza a ficção, na medida em que a voz narrativa situa no passado o mundo da obra. "É, pois, na refiguração do tempo que a narrativa histórica e a narrativa ficcional se interceptam, sem se confundirem" (ibid.).

Dessa forma, pode-se considerar que as duas formas de conhecimento histórico aquela da História-arte e a da História-ciência - complementam-se na base de um discurso narrativo comum que une também, como formas simbólicas, História e Ficção (NUNES, 1988).

Com o advento da virada hermenêutica das Ciências Sociais, ocorrida na década de 1970, fundada em teóricos como Paul Ricoeur, as vivências humanas e o mundo passaram a 
ser vistos como textos, o que promoveu a busca por diferentes instrumentos e estratégias metodológicas para lidar com estas novas leituras de mundo (GARNICA, 2005).

Neste período, também se consolida uma teoria narrativista com a tentativa de ratificar uma não equivalência entre passado e história, ou seja, o passado existiu, mas só poderia ser estudado através de práticas discursivas limitadas, que não esgotam as interpretações sobre ele. Não existe no passado uma realidade para se desvelar, mas sim, um sentido que é inventado pelos historiadores. Esta invenção surge, em grande parte, pela maneira como os historiadores escrevem a história, pois esta escrita não é um meio pelo qual apenas se relata a pesquisa histórica, ela está imbuída de valores históricos e ideológicos que modificam a própria pesquisa.

Buscando discutir o modo como o Grupo de Pesquisa em História Oral e Educação Matemática - GHOEM vem trabalhando a construção de narrativas historiográficas, optamos por vincular um esboço das questões envolvidas na produção e análise de narrativas pessoais com um exemplo de como esse exercício tem se efetivado.

\section{Experiência nas narrativas da História Oral}

Entendida como uma metodologia de pesquisa, a História Oral anuncia a necessidade de cuidados na construção de narrativas a partir de situações de entrevista, para, então, voltarse a outros cuidados (vinculados a qualquer tipo de fonte) no processo de construção desses registros mediante as questões feitas pelo pesquisador. Os rastros, os sinais, devem ser procurados em um terreno não sedimentado, movente e plural. Procurados, pois um documento só fala se é interrogado.

Para se tentar ler e interpretar alteridades dá-se conta de que o pesquisador compõe suas narrativas e entra numa negociação na qual existem inúmeros intérpretes e significações. Lida-se com a individualidade que cada um quer imprimir a seu relato, com imagens cristalizadas, institucionalizadas, com dramas e aflições.

Considerar a História Oral como metodologia de pesquisa implica, além da legitimação da coleta e análise de dados biográficos e narrativos enunciados por indivíduos particulares, a criação de uma autoidentidade ao contarmos nossas próprias histórias e reconhecermos a nós mesmos nessas narrativas. Independente de serem essas histórias 
verdadeiras ou falsas, tanto a ficção quanto a história verificável nos permitem uma identidade (RICOEUR apud LARROSA, 2005, p. 41).

Narrar é contar uma história, narrar-se é contar nossa história ou uma história da qual também somos, fomos ou nos sentimos personagens. Esse contar, é importante ressaltar, se dá sempre em direção a alguém. Desse modo, a narração prevê um posicionamento frente ao outro.

As narrativas oferecem em si a possibilidade de uma análise, se concebermos análise como um processo de produção de significados a partir de uma retroalimentação que se inicia quando o ouvinte/leitor/apreciador de um texto se apropria deste texto, de algum modo, tecendo significados que são seus, mesmo que produzidos de forma compartilhada com o autor do texto, e constrói uma trama narrativa própria que será ouvida/lida/vista por um terceiro, que, por sua vez, retorna ao início do processo.

Toda narrativa tem, como ressaltado há pouco, como participantes em sua constituição, autor e ouvinte. Aquele que narra o faz sempre em direção a alguém e este alguém (que fia e tece, nos termos de Walter Benjamin) participa da narração ao mostrar-se mais ou menos interessado, solicitando (com gestos, olhares...) ênfases, abreviações.

A compreensão de uma realidade, por qualquer tipo de análise, tendo em vista os relatos, as narrativas, apoiadas em visões de mundo, versões sobre um determinado acontecimento, hábitos e práticas, inclui (ou pode incluir) a compreensão dos modos de narrar do outro: os modos pelos quais o outro atribui significado às suas próprias experiências. Mas será que é realmente possível perceber as práticas e as experiências de um sujeito narrador? Ou ainda: prática e experiência se deixam narrar?

Preliminarmente, na tentativa de diferenciarmos prática de experiência, chamamos à cena Jorge Larrosa, que faz algumas ressalvas em relação ao uso da palavra "experiência". Ela não deve ser entendida, segundo este autor, como um modo de conhecimento inferior, ou considerada apenas como um ponto de partida para um conhecimento, ou ainda tomada como um empecilho para "um conhecimento verdadeiro" (LARROSA, 2005, p. 3). Com a intenção de legitimar a experiência, Larrosa aponta algumas precauções necessárias: primeiro, devemos livrar a palavra "experiência" de sua conotação empírica, isto é, separá-la de “experimento". Depois, é preciso negar à experiência qualquer dogmatismo ou pretensão de autoridade e, também, diferenciar experiência de prática, pensando aquela "não a partir da ação, mas da paixão, a partir de uma reflexão do sujeito sobre si mesmo do ponto de vista da 
paixão" (LARROSA, 2005, p. 4). Por fim, há que se evitar a tentação de fazer da experiência um conceito, bastando tomá-la como "um modo de habitar o mundo de um ser que existe, de um ser que não tem outro ser, outra essência além de sua própria existência - corporal, finita, encarnada no tempo e no espaço - com outros.” (ibid.)

O historiador deve explicar os episódios com os quais está tratando, não devendo caracterizá-los como modelos do mundo; deve incorporar as práticas do cronista, principalmente daqueles seus representantes clássicos (os cronistas medievais) que, segundo Benjamin (1994), são os precursores da historiografia moderna: o historiador deve, portanto, promover o encontro dos fios históricos com os pequenos detalhes da vida cotidiana.

Assim sendo, poderíamos vislumbrar uma compreensão a partir daquilo que chamamos de uma análise possível a partir de narrativas. A tentativa proposta é, face às várias versões apresentadas, trabalhar cada uma delas, já que são sempre lacunares, considerando-as como modos dos narradores se narrarem e constituírem suas verdades como sujeitos (GARNICA, 2007, p. 61), admitindo sempre uma certa distinção entre o que é vivido e o que é narrado. A análise narrativa desempenharia o papel de constituir o significado das experiências dos narradores mediante a busca de elementos unificadores e idiossincráticos, buscando com isso um desvelamento do modo autêntico da vida individual dos depoentes e da situação/contexto investigado.

Com a intenção de tecer considerações quanto a uma possibilidade de análise de narrativas, Bruner (1997) sugere que existem dois modos de funcionamento cognitivo, cada um fornecendo diferentes modos de ordenamento de experiência, de construção da realidade.

O primeiro é o modo paradigmático ou lógico científico que tenta perceber o ideal de um sistema formal e matemático de descrição e explicitação. Ele emprega a categorização na conceituação e nas operações pelas quais as categorias são estabelecidas, idealizadas e relacionadas umas às outras para formar uma sentença. $\mathrm{O}$ modo paradigmático trata de causas genéricas, de seu estabelecimento e faz uso de procedimentos para assegurar a referência comprovável e testar a veracidade empírica. Sua forma de se expressar é regulada por uma necessidade de consistência e de não-contradição e seu domínio é definido por elementos observáveis - aos quais suas afirmações básicas se referem - e conduzido por hipóteses fundamentadas. (BRUNER, 1997). 
Sobre o modo narrativo, Bruner (1997) afirma que este parte do princípio de que as ações humanas são únicas e irrepetíveis. Sua riqueza de matizes não pode, então, ser exibida em direções, categorias ou proposições abertas.

A análise paradigmática de dados narrativos consiste, portanto, em um estudo de narrativas categorizando-as para se chegar a generalizações do grupo estudado buscando, em suas narrativas, temas comuns.

$\mathrm{Na}$ análise narrativa (de narrativas), a ênfase está na consideração de casos particulares e o produto desta análise aparece como uma nova narrativa, a explicitação de uma trama ou de argumentos que tornem os dados significativos, não em busca de elementos comuns, mas no destaque do que é singular e que, em suma, não aspira à generalização. $\mathrm{O}$ papel do investigador neste tipo de análise é configurar os elementos dos dados em uma história que os unifica e dá significado a eles com a intenção de mostrar o modo autêntico da vida individual sem manipular a voz de cada narrador (ou depoente). A trama pode estar construída de forma temporal ou temática, mas o importante é que possibilite a compreensão do porquê algo aconteceu. Aqui, a proposta é a de revelar o caráter único de um caso individual e proporcionar uma compreensão de sua complexidade particular ou de sua idiossincrasia (BOLIVAR, 2002, p. 52). Na análise narrativa de narrativas o pesquisador desempenha o papel de constituir significados às experiências dos narradores mediante a busca de elementos unificadores e de alteridade, supondo que, mediante esse procedimento, estaria desvelando o modo autêntico da vida individual.

Tais considerações sobre as narrativas nos motivaram e nos municiaram para enfrentar a constituição de narrativas específicas: aquelas que tornam explícitas versões sobre a história da educação matemática.

Algumas possibilidades de narrativas a partir de narrativas em pesquisas educacionais vêm sendo exercitadas pelo Grupo de História Oral e Educação Matemática (GHOEM), pois um de seus objetivos é constituir um referencial para a utilização da História Oral como recurso às pesquisas em Educação Matemática. A constituição desse referencial vem acontecendo em trajetória, isto é, ao mesmo tempo em que investigações específicas vão sendo desenvolvidas, o referencial teórico-metodológico vai sendo estruturado. A contribuição dessas investigações, além da constituição desses referenciais, é a elaboração de um mapeamento histórico sobre a formação de professores de Matemática no Brasil, um estudo vinculado à História da Educação Matemática brasileira. Dentre os muitos trabalhos 
produzidos pelo grupo que, em 2012, completou 10 anos de atuação, destacamos, a seguir, algumas que trabalharam em suas análises com exercícios de análise narrativa.

\section{Narrativas sobre formação de professores}

Em Cury (2011), o autor apresenta uma narrativa (dentre muitas outras possíveis) sobre a constituição de cursos de formação de professores de Matemática e das instituições formadoras do estado do Tocantins, explicitando suas compreensões obtidas a partir dos discursos, dos dados, das circunstâncias, de como as histórias de diferentes pessoas, registradas em seus depoimentos, nos auxiliam a compreender um cenário específico. Para elaboração de tal narrativa, o autor buscou em depoimentos, textos, documentos e em sua própria vivência pontos de convergência e de divergência, o que era recorrente e o que era singular, para compor uma narrativa que deve ser entendida como cerne da investida. E todo o caminhar do trabalho - o projeto, o levantamento de dados, o estudo de documentos e referências bibliográficas, a criação e o estudo das fontes constituídas a partir das entrevistas, os debates com o orientador e o grupo de pesquisa, a avaliação dos membros da banca de qualificação - alicerçaram a construção dessa interpretação sobre a institucionalização da formação de professores de Matemática no Tocantins. ${ }^{2}$

A narrativa sobre a formação dos professores de Matemática no Tocantins apresentada em Cury (2011) é uma criação, uma interpretação, tecida a partir de depoimentos e de vários outros documentos coletados durante nossa investigação. Ela não deve ser entendida como um resumo, mas como uma ressignificação de histórias ouvidas, lidas, observadas, vividas durante a pesquisa.

Trata-se do movimento de buscar, de perseguir pistas e rastros que o pesquisador executa como faz o caçador quando recria os passos da sua presa para segui-la, juntando peças e tomando suas incertezas em relação à história que escreve como ponto de partida para iniciar e, cada vez mais, aprofundar uma investigação na qual devem estar tanto quanto possível explícitas as intercambiantes relações que se tecem num contexto temporal e

\footnotetext{
${ }^{2}$ Não destaco neste texto a narrativa produzida em Cury (2011) citada no início para não extrapolar o limite para publicação. Mas este trabalho, bem como outros vários do GHOEM podem ser acessados pelo site www.ghoem.com.
} 
geográfico específico, um contexto, portanto, entendido como lugar de possibilidades historicamente determinadas.

Os nexos entre história e narração ligam diretamente a história a outras formas de inteligibilidade da realidade: o historiador, como fazia o caçador primitivo, aprende a capturar, a partir de pistas, rastros muitas vezes fugidios, fios de uma narrativa como a que tentamos tecer. Assim, a proposta feita por Cury (2011) é de que as análises narrativas possam ser histórias que se parametrizam pela intenção de escapar do dualismo causa-consequência e conscientemente optem por desviar-se da tentação de explicar o que não deveria/poderia ser explicado e de interpretar vidas de forma linear e objetiva. Em Cury (2011), por exemplo, a narrativa está conscientemente contaminada com suas percepções, registrando o que foi possível registrar, por ter sido julgado significativo, não só os elementos que foram apontados, mas toda a trajetória empreendida.

Em Souza (2011), são exercitados diversos estilos textuais para a composição de uma tese no estilo multipaper. Artigos, inclusive em coautoria com orientandos de iniciação científica, textos descritivos, análise temática (com viés paradigmático) e uma análise narrativa compõe este trabalho. Esse exercício de análise narrativa não foca, entretanto, a temática da tese (qual seja, compreender o ensino de Matemática no contexto do Grupo Escolar Eliazar Braga), mas o próprio processo investigativo que permitiu sua efetivação.

Se uma das abordagens mobilizadas no GHOEM é a de que o professor se constitui enquanto tal no momento mesmo em que se narra frente ao outro, o exercício proposto em Souza (2011) é de compreensão do processo de pesquisa, suas idas e vindas e do como essa mobilidade, sua percepção e narração permitem que o pesquisador se constitua como tal enquanto se narra em investigação à comunidade da Educação Matemática. Desse modo, expectativas, orientações de membros da banca e de outros pesquisadores, ações individuais e conjuntas, parcerias com agências de fomento e grupo de pesquisa são articuladas revelando opções e encaminhamentos (normalmente indicados, na forma de resultado, em capítulos de metodologia), mas principalmente, os enfrentamentos que se colocam como decisivos na formação do pesquisador.

As ações e subversões possíveis de serem mapeadas nesse exercício analítico são, certamente, potencialidades de um movimento que não busca pela generalização, mas reconhece e respeita as diversas marcas de individualidade do pesquisador, do professor, daquele que se constitui na narração frente a um outro. 
Embora nem todos os exercícios analíticos propostos em Souza (2011) sejam de abordagem narrativa, este trabalho permitiu a constituição de dez narrativas a partir de entrevistas com antigos professores, diretora e alunos do Grupo Escolar Eliazar Braga, de Pederneiras/SP, e de outras pequenas narrativas construídas por alunos de 7 a 10 anos a partir de diálogos com seus avós e vizinhos sobre a época do Grupo Escolar. A produção de narrativas permite um olhar para práticas comumente não registradas em atas (como as de reuniões pedagógicas analisadas nessa tese), em fotografias (na época em estudo, geralmente montadas e distribuídas com o fim de participar dos álbuns de família, popularizando a ideia de escola como disciplinadora) e jornais escolares (produzidos para divulgar ações consideradas promissoras da instituição). Nas entrevistas pode-se compreender o comportamento dos alunos fora da pose, as notícias não divulgadas nos jornais e os bastidores das reuniões pedagógicas. Essa possibilidade não traz e não deve trazer a perspectiva de comparação qualitativa entre fontes. Não é disso de que se trata, mas das diferenças e potencialidades que cada fonte traz para a pesquisa e, por conta do foco deste texto, das potencialidades da narrativa para os estudos em História da Educação Matemática.

As entrevistas realizadas pela pesquisadora e os contos produzidos pelos alunos estruturam-se, na textualização, como narrativas fluentes de histórias e experiências de vida. O trabalho com essas produções permitem diferenciar a análise de narrativas da análise narrativa, ambas exploradas em Souza (2011) com o intuito de compreender as práticas cotidianas do Grupo Escolar Eliazar Braga (ensino, estrutura e organização pedagógica, papel dos uniformes, educação cívica, brincadeiras típicas, concepções de educação, preparação de aulas, materiais concretos no ensino da Matemática, entre outras).

Já em Silva (2007), o tratamento e a teorização de narrativas, sob a vertente da História Oral, teve como objetivo analisar o processo de constituição da identidade do Centro de Educação Matemática (CEM) - grupo que atuou, sobretudo, nos anos de 1984 a 1997 na cidade de São Paulo e que se apresenta como “equipe prestadora de serviços de assessoria e consultoria especializada em Educação Matemática a escolas, Diretorias de Ensino, Secretarias de Educação e instituições especializadas como a Coordenadoria de Estudos e Normas Pedagógicas - CENP e a Fundação para o Desenvolvimento da Educação - FDE da Secretaria de Educação do Estado de São Paulo" (SILVA, 2007).

Nesse trabalho, identidade foi concebida como processos de produção de significados - ou invenções, estas vistas como o avesso de origem, de expressões do real - para atores 
pessoais, coletivos ou coisas, que se constituem em meio a discursos com base em um atributo cultural; ou, ainda, um conjunto de atributos culturais interrelacionados que prevalecem sobre outras fontes de significado. Pautados nessa desconcepção de identidade, foram construídos e apresentados diferentes processos de produção de significados para o CEM, ou seja, diferentes identidades desse grupo. Para tanto, foram elaborados e analisados quinze depoimentos, registros textuais de fontes orais, dos quais dez são de integrantes desse grupo, e a partir desses registros foram constituídos alguns fragmentos. Como um segundo objetivo da pesquisa, buscou-se conceber distintas teorizações da identidade do grupo pesquisado com vistas a apresentar distintos processos de produção de significados para este grupo a partir de um olhar externo a ele. Tais teorizações, apresentadas em quatro fragmentos, estiveram, respectivamente, fundamentadas em René Descartes (Fragmento XI); Émile Durkheim, George Herbert Mead, Peter Berger \& Thomas Luckmann e, sobretudo, Norbert Elias (Fragmento XII); Etienne Wenger (Fragmento XIII) e Michel Foucault (Fragmento XIV). Considera-se razoável abarcar três perspectivas que diferem, principalmente, pelo lugar a partir do qual o sujeito é formado no mundo: no seu 'interior' - perspectiva cartesiana -; na mistura do seu 'interior' com o mundo cultural exterior' - perspectiva sociológica -; ou pelas formas como é representado e interpelado no mundo cultural - perspectiva pós-moderna ${ }^{3}$.

As narrativas - resultantes das textualizações das entrevistas - versam sobre as histórias dos depoentes no e sobre o grupo e têm como matéria prima a memória. Esses discursos narrativos são, dessa forma, os primeiros lugares onde as primeiras identidades do CEM são constituídas no trabalho. A partir dessas narrativas e de referenciais teóricos distintos foram elaborados diferentes discursos científicos, isto é, diferentes modos de produzir significados para a constituição da identidade do CEM sob o ponto de vista do saber científico, e, em meio a eles, constituir novas identidades para esse grupo.

Visando abranger todos os aspectos - inclusive linguísticos - das diferentes teorias da identidade na análise das narrativas sobre o CEM, o texto foi configurado sob os moldes da análise narrativa, mas segundo os quatro diferentes discursos científicos. Para tanto, textos literário-fictícios foram produzidos - baseados na obra dos heterônimos de Fernando Pessoa situados em fragmentos isolados, estando cada um deles na forma de diálogos narrativos entre

\footnotetext{
${ }^{3}$ No pensamento filosófico pós-moderno, inspirado no pós-estruturalismo (representado por Foucault e Derrida), o sujeito não é o centro da ação social como no ponto de vista sociológico e, sobretudo, cartesiano. Ele não pensa, fala e produz: ele é pensado, falado e produzido. É, portanto, uma ficção.
} 
a pesquisadora e uma personagem-heterônimo (inventou-se novos depoentes para a pesquisa). Os conteúdos de cada um desses fragmentos versam sobre a análise do processo de constituição das identidades do CEM segundo as bases teóricas aceitas e vividas pela personagem em questão. A ideia geral foi que cada personagem auxiliasse a pesquisadora na análise de tal processo de modo que juntas pudessem realizar uma leitura plausível dos parâmetros teóricos adotados.

A estratégia heteronímica ajudou a apontar que os aspectos da identidade são determinados exclusivamente pelo modo como ela encara esse conceito, assim como também pela situação em que as pessoas encontram-se inseridas no momento em que articulam sobre identidade.

\section{Considerações}

No modo narrativo de conhecimento, os fatos são dispostos em sequência contextualizada e não em categorias. Segundo Bolívar (2012),

[...] o razonamiento narrativo funciona por medio de una colección de casos individuales en que de uno se pasa a otro, y no de un caso a una generalización. La preocupación no es identificar cada caso bajo una categoría general, el conocimiento procede por analogía, donde un individuo puede o no ser similar a otros. Lo que importa son los mundos vividos por los entrevistados, los sentidos singulares que expresan y las lógicas particulares de argumentación que despliegan (p.12).

Consideramos, a partir do desenvolvimento dos trabalhos acima indicados, que a análise narrativa se faz preciosa não apenas por deixar fluir para o leitor uma narrativa e um narrador específicos, mas, como leitor/ouvinte e, portanto, autor da significação, por torná-lo parte desse exercício. Para nós, a análise narrativa em história oral é um exercício de amalgamar a ficção que o outro é à ficção que somos nós, ou seja, é assumir a interferência no texto (desde a transcrição - e mesmo antes disso) por meio dos significados que são produzidos para aquele texto.

A ficção tem nos ajudado - como fonte (na mobilização de contos e outros textos como recursos para pensar a História da Educação Matemática) ou como fundante no processo de significação - a trabalhar a ideia de convivência entre saberes perspectivos, inclusive no que concerne à ciência; como também a abarcar a noção de que a identidade é invenção que se constitui através das linguagens narrativa e científica. Com leitura das obras 
do poeta Fernando Pessoa ${ }^{4}$, percebemos que a ficção nos permite "ser um outro cognitivo" que criamos ao denotar determinada posição.

Nesse sentido, Albuquerque Junior (2011) chama a atenção para o homem em estado de palavra:

[...] o homem que se conta não é o mesmo homem que vive, mesmo quando narra sua própria vida. Quando faz memória ou autobiografia, o sujeito narrador não coincide com o sujeito narrado, o sujeito da narrativa não é o mesmo personagem contado. Porque o sujeito da narrativa é um sujeito em estado de vida, em carne e osso, é um sujeito em que corre sangue nas veias. Já o sujeito narrado é um sujeito em estado de palavra, é feito de papel, é um sujeito em que corre tinta nas veias. O historiador que pretende estar falando do sujeito de carne e osso, falará na verdade do sujeito de papel e tinta que chega até ele mediante suas distintas formas de representação, embora estas formas de representação permitam a ele, pelo menos, garantir que o seu personagem realmente fez parte do passado. $\mathrm{O}$ historiador dará a ele uma nova vida, de tinta e papel, embora faça parte do pacto de leitura entre o leitor e o autor do texto historiográfico acreditar que ali se fala do sujeito de carne e osso que um dia viveu no passado (p. 254).

Os trabalhos desenvolvidos pelo GHOEM, seja na construção de narrativas ou em suas análises (paradigmáticas ou narrativas), pautados na História Oral, visam a criação de uma gama de fontes para as pesquisas (em Educação Matemática ou não). Ao exercitar a análise de narrativas, os pesquisadores desse grupo evidenciam seu olhar na busca, ora por convergências, ora por singularidades, constituindo professores de papel e tinta, articulando memórias.

Ao respeitar as marcas de singularidade das narrativas, constrói-se uma perspectiva não de lacunas (que podem fazer sentido quando se concebe a existência de um todo), mas de interminável e contínua construção de uma História da Educação Matemática que não se fez ou faz toda. Nos trabalhos aqui citados, um exemplo é a tese de Silva (2007) que tematiza a identidade e enfatiza que nenhum dos fragmentos de identidade apresentados, em particular, e nem todos, juntos, definem uma constituição (interna) do CEM. Cada um e todos eles (mais todos os que poderão vir a ser constituídos pelo leitor) permitem que um grupo apareça, sobrepondo-o às relações entre uns e outros, situando-o em relação aos uns e aos outros, definindo sua diferença, sua irredutibilidade e sua desigualdade, criando como que um campo de exterioridade.

\footnotetext{
${ }^{4}$ Fernando Pessoa (1888-1935) foi um poeta português que escreveu sob múltiplas personalidades, heterônimos, como Ricardo Reis, Álvaro de Campos e Alberto Caeiro, tendo sido estes, elementos da maior parte dos estudos sobre a sua vida e obra.
} 
Dessa forma, a produção e análise de narrativas em Educação Matemática tem permitido a construção de diversas e diferenciadas (no sentido de ir além de práticas normativas) perspectivas, fomentando uma contínua compreensão dos processos de formação e ensino de/em Matemática.

\section{Referências}

ALBUQUERQUE JUNIOR, D. M. de. Em Estado de Palavra: quando a história não consegue que se meta fora a literatura. In: FLORES, M. B. R.; PIAZZA, M. de F. F.(Org.). História e arte: movimentos artísticos e correntes intelectuais. Campinas, São Paulo: Mercado de Letras, 2011. p. 249261.

BENJAMIN, W. O Narrador: considerações sobre a obra de Nikolai Leskov. In: BENJAMIN, W. Magia e Técnica, Arte e Política: ensaios sobre a literatura e a história da cultura. São Paulo: Brasiliense, 1994. p. 197-221.

BOLIVAR, A. B. 'De nobis ipsis silemus?': Epstemoligia de la investigación biográfico-narrativa en educación. In Revista Eletrónica de Investigación Educativa, Barcelona. 2002. v. 11, n. 1. Disponível em: <http://redie.ens.uabc.mx/vol4no1/contenido-.html>. Acesso em: 05 abr. 2006.

BOLÍVAR, A. Dimensiones epistemológicas y metodológicas de La investigación (auto)biográfica. In: ABRAHAO, M. H. (Org.). Pesquisa (auto)biográfica: lugares, trajetos e desafios. V Congresso Internacional de Pesquisa (Auto)Biográfica (V CIPA). Porto Alegre: PUCRS, 2012, p. 27-69.

BRUNER, J. Atos de Significação. Porto Alegre: Artes Médicas, 1997.

CURY, F. G. Uma História da Formação de Professores de Matemática e das Instituições Formadoras do Estado do Tocantins. 2011. 235 f. Tese (Doutorado em Educação Matemática) Instituto de Geociências e Ciências Exatas, Universidade Estadual Paulista, Rio Claro, 2011.

GARNICA, A. V. M. Um Tema, Dois Ensaios: Método, História Oral, Concepções, Educação Matemática. 2005. 203 f. Tese (Livre-Docência) - Faculdade de Ciências, Universidade Estadual Paulista, Bauru, 2005.

GARNICA, A. V. M. Historia Oral em Educação Matemática. Guarapuava: SBHMat, 2007.

LARROSA, J. Algunas notas sobre la experiencia y sus lenguajes. In: BARBOSA, J. R. L. L. (Org.). Trajetórias e perspectivas da formação de educadores. São Paulo: UNESP, 2005. P. 19-24.

NUNES, B. Narrativa Histórica e Narrativa Ficcional. In: NUNES, B. et al. (Org.). Narrativa: Ficção e História. Rio de Janeiro: Imago, 1988. p. 9-35.

SEVCENKO, N. No Princípio era o Rítmo: as raízes xamânticas da narrativa. In: REIDEL, D. C. (Org.). Narrativa: Ficção e História. Rio de Janeiro: Imago, 1988. p. 120-136.

SILVA, H. Centro de Educação Matemática: fragmentos de identidade. 2007. 448 f. Tese (Doutorado em Educação Matemática) - Instituto de Geociências e Ciências Exatas, Universidade Estadual Paulista, Rio Claro, 2007. 
SOUZA, L. A. de. Trilhas na construção de versões históricas sobre um Grupo Escolar. 2011. 420 f. Tese (Doutorado em Educação Matemática) - Instituto de Geociência e Ciências Exatas,

Universidade Estadual Paulista, Rio Claro, 2011.

Submetido em Agosto de 2013. Aprovado em Janeiro de 2014. 